\title{
Description of a methodological approach to verify the outcome-optimization of tailored therapeutic choices and test application to PCI vs. CABG
}

\author{
Stefano Di Bartolomeo ${ }^{1}$ Paolo Guastaroba ${ }^{2}$, Daniela Fortuna ${ }^{2}$, Rossana De Palma ${ }^{2}$, Roberto \\ Grilli $^{2}$
}

1. Regional Agency for Health and Social Care of Emilia-Romagna/Azienda Ospedaliero-Universitaria di Udine, Bologna, Italy. 2. Regional Agency for Health and Social Care of Emilia-Romagna, Italy

Correspondence: Stefano Di Bartolomeo. Address: Regional Agency for Health and Social Care of Emilia-Romagna/Azienda Ospedaliero-Universitaria di Udine, Viale Aldo Moro 21, 40127 Bologna, Italy. E-mail:

stefano.dibartolomeo@uniud.it

Received: October 28, 2012

Accepted: December 23, 2012

Online Published: December 28, 2012

DOI : $10.5430 /$ jha.v2n2p47

URL: http://dx.doi.org/10.5430/jha.v2n2p47

\section{Abstract}

Background: The scientific evidence guiding the choice between Percutaneous Coronary Intervention (PCI) and Bypass Graft Surgery (CABG) is inconclusive. Yet, tailoring the choice to the patients' characteristics is generally considered important to optimize outcomes.

Objectives: To verify the supposed outcome benefits of tailoring the choice of the revascularization procedure.

Methods: We calculated a propensity score (PS) - i.e. the probability, given the patients' characteristics, of undergoing one of the two alternative procedures - for the 11,750 patients with severe coronary disease who underwent coronary revascularization between 2002 and 2008 in an Italian region. Then we investigated the effect-modification of the PS on the Hazard Ratios (HR) of PCI vs. CABG for death, myocardial infarction, stroke and repeat revascularization with a likelihood ratio test and by visual inspection.

Results: Only the least important outcome (repeat revascularization) significantly differed across deciles of PS ( $p=0.05$ ) and its graphical trend supported a favorable effect of the decision process.

Conclusions: In agreement with the current scientific uncertainty, but contrary to common opinion, the medical decision process between PCI and CABG based on demographic and clinical factors is marginally capable of optimizing the post-procedural outcomes. The study relies on the assumption that the variables considered by clinicians were among those included in the PS.

\section{Key words}

Outcome and process assessment (health care), Coronary disease, Coronary artery bypass, Angioplasty, Patient selection, Propensity score

\section{I ntroduction}

When two therapeutic options are alternative, it is important to know whether their outcomes are uniform across all types of patients or change in subgroups having some characteristics. These characteristics then receive careful consideration by 
the clinicians who decide the indication. In statistical terms, the former condition is called uniformity of effects, while, in the latter, a so-called interaction (or effect-modification) must be present between any of the patient characteristics and the outcome of the therapeutic procedures.

In the case of severe Coronary Artery Disease (CAD) (left main or multivessel involvement) - the scientific evidence ${ }^{[1-9]}$ supporting the interventional choice between Percutaneous Coronary Intervention (PCI) and Coronary Artery Bypass Graft (CABG) is inconclusive. Uncertainty surrounds not only the 'best' technique in absolute terms (i.e. better for all or most patients), but also, more importantly, the effect-modifier factors that could make either technique preferable in the specific patient. For example, in diabetic patients CABG was preferable according to some studies ${ }^{[10]}$, but not to others ${ }^{[11]}$.

Notwithstanding this, tailoring the choice to the patient's characteristics is often advocated as important for outcome optimization ${ }^{[4]}$, as if the clinicians' judgment could attain what the literature has not yet demonstrated.

The objective of this study is therefore to verify retrospectively if tailoring the interventional choice to the patient's characteristics had an actual impact on the outcome of coronary revascularization.

\section{Materials and methods}

\subsection{Setting and sources}

Emilia-Romagna is an Italian region with about $4.5^{*} 10^{6}$ inhabitants where six hospitals perform cardiac surgery and interventional cardiology and ten hospitals perform only interventional cardiology and have defined referral policies to one cardiac-surgery facility.

The main data sources for this study were the Regional Registry of Coronary Angioplasties and the Regional Registry of Cardiac Surgery Procedures. The former, established in 2002, collects demographic and clinical data on the procedures performed in all the interventional-cardiology centers of the region and currently contains about 95,000 records. The latter, also established in 2002, gathers similar data from the regional centers of cardiac surgery and currently contains about 36,000 records. More information about these registries is available from previous publications ${ }^{[12,13]}$.

We obtained further information by matching the patients from the above registries with their corresponding records in two other regional data sources: the Mortality Registry and the Database of Hospital Admissions. A regional unique patient identifier facilitated the matching.

\subsection{Patient selection}

All patients whose left main or at least two other coronary vessels were treated for CAD with PCI or CABG in Emilia Romagna from July/1/2002 to December/31/2008 were eligible.

The exclusion criteria were: missing information on the number of treated vessels, concomitant valvular disease treatment, patient not resident in Emilia Romagna, previous coronary revascularization, recent ( $<24$ hours) ST-elevation myocardial infarction, and moderate to severe valvulopathy or shock. The follow-up extended through December 2010.

Given the observational design of the study and the anonymity of the databases available for analysis, the approval of the ethical committee was not necessary.

\subsection{Procedures}

The definition of diseased vessel was a stenosis $>50 \%$. 
Table 1. Distribution of baseline covariates and standardized differences

\begin{tabular}{|c|c|c|c|}
\hline & $\begin{array}{l}\text { PCI N=6246 } \\
(\mathrm{N}=5593)^{*}\end{array}$ & $\begin{array}{l}\text { CABG N=5504 } \\
(\mathrm{N}=4208)^{*}\end{array}$ & Standardized Difference* $*$ \\
\hline \multicolumn{4}{|l|}{ Age (\%) } \\
\hline$<61 \mathrm{yr}$ & $24.3(24.8)$ & $20.1(20.4)$ & $10.0(10.4)$ \\
\hline 61 to $75 \mathrm{yr}$ & $46.7(47.5)$ & $58.0(56.6)$ & $-22.5(-18.2)$ \\
\hline$>75 \mathrm{yr}$ & $28.9(27.6)$ & $21.9(22.9)$ & $16.2(10.9)$ \\
\hline \multicolumn{4}{|l|}{ Gender (\%) } \\
\hline Male & $73.7(74.7)$ & $80.4(79.3)$ & $-15.9(-10.94)$ \\
\hline \multicolumn{4}{|l|}{ Year of admission (\%) } \\
\hline 2002 & $3.3(3.1)$ & $8.4(6.0)$ & $-21.8(-13.8)$ \\
\hline 2003 & $12.0(12.7)$ & $20.5(21.7)$ & $-23.2(-24.1)$ \\
\hline 2004 & $15.9(16.4)$ & $18.4(18.9)$ & $-6.6(-6.6)$ \\
\hline 2005 & $17.6(17.4)$ & $14.7(15.0)$ & $8.0(6.5)$ \\
\hline 2006 & $16.9(16.5)$ & $13.2(13.0)$ & $10.4(9.7)$ \\
\hline 2007 & $17.6(17.7)$ & $13.5(13.8)$ & $11.2(10.7)$ \\
\hline 2008 & $16.7(16.2)$ & $11.2(11.5)$ & $15.6(13.5)$ \\
\hline \multicolumn{4}{|l|}{ Hospital (\%) } \\
\hline A & $5.3(5.6)$ & $5.1(5.2)$ & $0.9(1.7)$ \\
\hline $\mathrm{B}$ & $2.0(1.5)$ & $6.2(1.5)$ & $-21.3(0.38)$ \\
\hline $\mathrm{C}$ & $5.1(5.3)$ & $8.8(9.4)$ & $-14.7(-15.7)$ \\
\hline $\mathrm{D}$ & $18.0(18.1)$ & $8.1(10.4)$ & $29.6(22.2)$ \\
\hline $\mathrm{E}$ & $3.7(3.7)$ & $7.4(5.0)$ & $-16.1(-6.3)$ \\
\hline $\mathrm{F}$ & $8.7(7.4)$ & $5.9(7.6)$ & $10.7(-0.8)$ \\
\hline G & $2.3(2.3)$ & $2.3(2.8)$ & $0.3(-2.7)$ \\
\hline $\mathrm{H}$ & $7.1(7.5)$ & $11.6(12.4)$ & $15.5(-16.1)$ \\
\hline I & $9.7(9.9)$ & $7.8(9.6)$ & $7.0(0.9)$ \\
\hline $\mathrm{L}$ & $6.9(6.3)$ & $6.7(6.6)$ & $0.65(-1.2)$ \\
\hline M & $15.7(16.4)$ & $5.0(6.4)$ & $35.7(31.9)$ \\
\hline $\mathrm{N}$ & $4.7(4.9)$ & $7.2(7.8)$ & $-10.4(-12.1)$ \\
\hline $\mathrm{P}+\mathrm{Q}$ & $2.5(2.1)$ & $9.6(6.6)$ & $-30.2(-22.0)$ \\
\hline $\mathrm{R}+\mathrm{S}$ & $8.3(8.9)$ & $8.4(8.8)$ & $-0.31(0.5)$ \\
\hline \multicolumn{4}{|l|}{ Number and type of diseased vessels (\%) } \\
\hline 1, only LMCA & $1.71(0)$ & $0.16(0)$ & $16.1(\mathrm{~N} / \mathrm{A})$ \\
\hline 2, without LMCA & $2.58(1.8)$ & $1.6(1.8)$ & $6.6(-0.1)$ \\
\hline 2, with LMCA & $55.6(54.3)$ & $13.1(15.7)$ & $99.9(88.5)$ \\
\hline 3, without LMCA & $4.9(5.3)$ & $13.8(11.5)$ & $-31.0(-22.6)$ \\
\hline 3, with LMCA & $32.7(35.8)$ & $39.1(46.4)$ & $-13.4(-21.7)$ \\
\hline 4 & $2.6(2.8)$ & $32.2(24.6)$ & $-84.8(-66.6)$ \\
\hline Ejec. fraction $<35 \%(\%)$ & $6.1(5.3)$ & $5.3(5.9)$ & $3.7(-2.6)$ \\
\hline Previous myocardial infarction (\%) & $19.5(20.2)$ & $37.1(37.2)$ & $-39.7(-38.2)$ \\
\hline Congestive heart failure $(\%)$ & $19.0(18.2)$ & $19.2(20.2)$ & $-0.5(-5.0)$ \\
\hline Unstable angina or non-ST-elevation MI (\%) & $55.8(54.8)$ & $49.7(50.2)$ & $12.2(9.4)$ \\
\hline Familiarity of CAD (\% of non-missing) & 21.6 & $28.2(28.5)$ & N/A \\
\hline Missing data & $10.6(7.9)$ & $21.2(14.6)$ & $-29.4(-19.2)$ \\
\hline Diabetes $(\%)$ & $22.7(23.2)$ & $26.6(27.1)$ & $-9.1(-9.0)$ \\
\hline Hypertension ( $\%$ of non-missing) & $76.9(77.5)$ & $80.7(81.0)$ & N/A \\
\hline Missing data & $2.1(0.8)$ & $2.0(1.1)$ & $0.3(-3.4)$ \\
\hline Smoking ( $\%$ of non-missing) & $24.1(22.4)$ & $20.4(20.0)$ & N/A \\
\hline Missing data & $4.6(3.4)$ & $11.0(7.0)$ & $-24.3(-16.2)$ \\
\hline Cerebrovascular disease $(\%)$ & $10.9(10.6)$ & $15.2(14.5)$ & $-12.7(-11.8)$ \\
\hline Peripheral vascular disease (\%) & $7.7(7.3)$ & $12.1(11.1)$ & $-14.8(-13.1)$ \\
\hline Renal failure $(\%)$ & $6.3(5.4)$ & $5.1(4.8)$ & $5.4(2.9)$ \\
\hline Chronic obstructive pulmonary disease (\%) & $8.5(7.7)$ & $9.5(9.3)$ & $-3.3(-5.6)$ \\
\hline Malignancy diagnosed $\leq 2 \mathrm{yr}(\%)$ & $5.9(4.6)$ & $3.4(3.3)$ & $11.7(6.4)$ \\
\hline Gastric ulcer (\%) & $1.4(1.2)$ & $1.0(1.1)$ & $3.1(0.7)$ \\
\hline
\end{tabular}

* In round brackets the values of cases and percentages within the common support of propensity score (see methods for details); $\uparrow 100(\mathrm{pT} 1-\mathrm{pT} 2) /[\mathrm{pT} 1 *(1-\mathrm{pT} 1)+\mathrm{pT} 2 *(1-\mathrm{pT} 2)]$, where $\mathrm{pT}=$ proportion of $\mathrm{PCI}$ cases and $\mathrm{pT} 2=$ proportion of $\mathrm{CABG}$ cases. A standardized difference greater than 10 per cent represents meaningful imbalance in a given covariate. $\mathrm{PCI}=\mathrm{Percutaneous}$ coronary intervention, $\mathrm{CABG}=$ Coronary artery bypass grafting, $\mathrm{LMCA}=\mathrm{Left}$ main coronary artery, $\mathrm{MI}=$ Myocardial infarction, $\mathrm{CAD}=$ Coronary artery disease 
All types of stents (i.e. bare metal or sirolimus-eluting or paclitaxel-eluting stent) were used, according to the interventionist's preference.

Standard bypass techniques were used for CABG operations. Whenever possible, the LAD was revascularized with the left internal thoracic artery. Multiple revascularizations were performed when possible with other arterial conduits or saphenous vein grafts.

Neither group of patients underwent routine follow-up angiography.

Repeat revascularization included target vessel revascularization only. In order not to spuriously include staged procedures, we considered only PCIs repeated $\geqslant 45$ days from the index one.

\subsection{Statistical analysis}

The classic definition of propensity score (PS) is the probability that an individual would have received a certain treatment (PCI in this case) based on that individual's observed pretreatment variables ${ }^{[14]}$. Usually, the PS is applied by various techniques in observational studies to balance covariates and thus control confounding ${ }^{[15]}$ when estimating the effect of the treatment relative to an alternative (e.g. no treatment or another treatment). Propensity models generally assume that this effect is the same for all subjects. However, if the treatment effect depends on patient-specific factors, then its estimate will vary across subgroups with different distributions of these factors ${ }^{[16]}$. This should be the case of PCI relative to CABG if tailoring the choice to demographic and clinical characteristics could actually optimize the outcomes. More specifically, the outcomes of one procedure relative to the other should improve when the propensity to receive that procedure is higher and, vice versa, worsen with decreasing propensity.

The PS was calculated by a logistic regression model whose binary dependent variable was PCI versus CABG and the independent variables were the demographic and clinical variables shown in Table 1 plus indicator variables for the year of admission and for the centre of the first, diagnostic angiogram. All main effects and first level interactions with stable estimates were included. The final model included 704 terms. The $\mathrm{C}$ statistics of this model was 0.912 .

Common support was then applied, i.e. the patients of either treatment-group with a PS outside the range of the counterfactual group were excluded. The PS was then recalculated on the remaining cases.

The effects on mortality, MI, repeat revascularization and stroke of PCI vs. CABG across the spectrum of patients' characteristics were assessed by Cox regression. The proportional hazard assumption was verified by examination of the $\log [-\log$ (survival)] curves and by testing of partial (Schoenfeld) residuals.

The Hazard Ratios (HR) of the various outcomes were calculated in each of the deciles of PS. We then assessed the significance of any difference across these strata with a Likelihood Ratio (LR) test with nine degrees of freedom between a model comprising of treatment (PCI vs. CABG) and PS deciles (nine indicator variables) and another model including also indicator variables for the products (interactions) between treatment and PS deciles. When the absences of events in one treatment group made the estimation impossible, deciles were grouped (deciles 1 and 2 and deciles 9 and 10 for MI, deciles 9 and 10 for revascularization) and the degrees of freedom reduced accordingly.

Missing data were managed by simple imputation (i.e. assigning another level for missing variables) when needed (hypertension, familiarity, smoke history).

\section{Results}

The characteristics of the whole population $(\mathrm{N}=11,750)$ are shown in Table 1. In the PCI group, more patients were in the extreme classes of age $(>75 \mathrm{yr}$ and $<61 \mathrm{yr}$ ) and suffered from unstable angina or malignancy. In the CABG group, more 
patients were in the intermediate ( 61 to $75 \mathrm{yr}$ ) class of age, the number of diseased vessels was larger, more patients had had a previous MI, were males, had cerebral or peripheral vascular disease. Strong differences concerning the year and hospital of admission were also present.

Table 2. Proportion of patients experiencing the various outcomes in each PS decile and by treatment group

\begin{tabular}{|c|c|c|c|c|c|c|c|c|}
\hline \multirow{3}{*}{ PS Decile* } & \multicolumn{8}{|c|}{ No. of events/total cases } \\
\hline & \multicolumn{2}{|c|}{ Mortality } & \multicolumn{2}{|c|}{ Myocardial infarction } & \multicolumn{2}{|c|}{ Repeat revascularization } & \multicolumn{2}{|l|}{ Stroke } \\
\hline & PCI & CABG & PCI & CABG & PCI & CABG & PCI & CABG \\
\hline 1 & $5 / 17$ & $106 / 964$ & $0 / 17$ & $44 / 964$ & $6 / 17$ & $79 / 964$ & $1 / 17$ & $46 / 964$ \\
\hline 2 & $15 / 71$ & $118 / 909$ & $9 / 71$ & 38/909 & $26 / 71$ & $51 / 909$ & $3 / 71$ & 34/909 \\
\hline 3 & $31 / 168$ & $92 / 812$ & $28 / 168$ & $33 / 812$ & $58 / 168$ & $47 / 812$ & $8 / 168$ & $42 / 812$ \\
\hline 4 & $67 / 371$ & $83 / 609$ & $44 / 371$ & $36 / 609$ & $96 / 371$ & $42 / 609$ & $15 / 371$ & $26 / 609$ \\
\hline 5 & $112 / 594$ & $65 / 386$ & $68 / 594$ & $15 / 386$ & $133 / 594$ & $26 / 386$ & $27 / 594$ & $20 / 386$ \\
\hline 6 & $135 / 764$ & $18 / 216$ & 98/764 & $7 / 216$ & $173 / 764$ & $12 / 216$ & $36 / 764$ & $9 / 216$ \\
\hline 7 & $119 / 835$ & $16 / 145$ & $114 / 835$ & $5 / 145$ & $210 / 835$ & $8 / 145$ & $32 / 835$ & $4 / 145$ \\
\hline 8 & $113 / 884$ & $6 / 96$ & $100 / 884$ & $6 / 96$ & $184 / 884$ & $5 / 96$ & $33 / 884$ & $2 / 96$ \\
\hline 9 & $129 / 928$ & $7 / 53$ & $90 / 928$ & $5 / 53$ & $197 / 928$ & $7 / 53$ & $33 / 928$ & $1 / 53$ \\
\hline 10 & $130 / 961$ & $1 / 18$ & $102 / 961$ & $0 / 18$ & $185 / 961$ & $0 / 18$ & $31 / 961$ & $1 / 18$ \\
\hline \multirow{2}{*}{ Total } & $856 /$ & $512 /$ & $653 /$ & $189 /$ & $1268 /$ & $277 /$ & 219/ & $185 /$ \\
\hline & 5593 & 4208 & 5593 & 4208 & 5593 & 4208 & 5593 & 4208 \\
\hline
\end{tabular}

$\mathrm{PS}=$ Propensity Score, $\mathrm{PCI}=$ Percutaneous coronary intervention, $\mathrm{CABG}=$ Coronary artery bypass grafting; *Decile 1 is most likely to receive $\mathrm{CABG}$ and decile 10 is most likely to receive $\mathrm{PCI}$

Six hundred fifty three patients of the PCI group had a PS higher than the maximum value (0.9906251) of the CABG group and 1,296 patients of the CABG group had a PS lower than the minimum value $(0.0028794)$ of the PCI group. These cases (16.6\%) should approximate the patients for whom an alternative treatment was not feasible, represent the equivalent of those judged non-randomizable in RCTs and were excluded, leaving 9,801 cases for further analysis.

The follow up ranged from to 24 to 90 months. The mean follow-up for survivors was 1,666 days. The proportional hazard assumption was confirmed in all models.

Table 2 displays the proportion of patients experiencing the various outcomes in each PS decile and by treatment group.

Table 3. Propensity-decile-specific Hazard Ratios of PCI vs. CABG for the various outcomes

\begin{tabular}{lllll}
\hline Decile of PS* & Mortality & $\begin{array}{l}\text { Myocardial infarction } \\
\text { HR (95\%CI) }\end{array}$ & $\begin{array}{l}\text { Repeat } \\
\text { revascularization }\end{array}$ & Stroke \\
\hline 1 & $3.11(1.27-7.63)$ & $\mathrm{n} / \mathrm{a}$ & $6.31(2.75-14.50)$ & $1.50(0.21-10.86)$ \\
2 & $1.74(0.99-3.03)$ & $2.96(1.38-6.34)$ & $9.38(5.80-15.16)$ & $0.86(0.21-3.62)$ \\
3 & $1.61(1.06-2.43)$ & $4.43(2.67-7.34)$ & $7.79(5.30-11.46)$ & $0.91(0.41-2.04)$ \\
4 & $1.40(1.01-1.93)$ & $2.03(1.30-3.17)$ & $4.34(3.01-6.24)$ & $0.91(0.46-1.78)$ \\
5 & $1.12(0.82-1.53)$ & $2.94(1.68-5.14)$ & $3.68(2.41-5.61)$ & $0.93(0.51-1.71)$ \\
6 & $2.14(1.32-3.46)$ & $4.19(1.94-9.03)$ & $4.67(2.60-8.40)$ & $1.06(0.50-2.22)$ \\
7 & $1.26(0.75-2.13)$ & $4.07(1.66-9.96)$ & $5.12(2.50-10.4)$ & $1.37(0.48-3.88)$ \\
8 & $2.14(0.94-4.86)$ & $1.86(0.81-4.24)$ & $4.47(1.84-10.87)$ & $1.79(0.43-7.49$ \\
9 & $1.07(0.50-2.30)$ & $1.01(0.41-2.51)$ & $1.73(0.81-3.68)$ & $1.79(0.24-13.11)$ \\
10 & $2.55(0.35-18.29)$ & $\mathrm{n} / \mathrm{a}$ & $\mathrm{n} / \mathrm{a}$ & $0.64(0.08-4.70)$ \\
Overall $\dagger$ & $1.48(1.27-1.73)$ & $2.82(2.25-3.54)$ & $5.25(4.37-6.32)$ & $1.03(0.77-1.38)$ \\
$P$ value for & & 0.19 & 0.05 & 0.99 \\
differences & 0.31 & & & \\
\hline
\end{tabular}

$\mathrm{PCI}=$ Percutaneous coronary intervention, $\mathrm{CABG}=$ Coronary artery bypass grafting PS=Propensity Score, $\mathrm{HR}=$ Hazard Ratio, CI= Confidence Interval; $*$ Decile 1 is most likely to receive $\mathrm{CABG}$ and decile 10 is most likely to receive PCI; $\uparrow$ Adjusted for deciles of propensity score 
Table 3 shows the HRs of the various outcomes of PCI vs. CABG across the deciles of PS and the p values of the LR test that assessed the homogeneity of these HRs. The outcomes are generally better with CABG, though this is not the focus of this study. More importantly, there is a substantial homogeneity across the ten categories, except for revascularization.

Figure 1 shows the behavior of the HRs across the PS deciles. If tailoring had had the expected impact, one would expect the risks of adverse events to decrease with the propensity to receive either treatment (i.e. a decreasing trend in the figure, where PCI is the numerator of the HR and PCI-propensity increases left to right on the $\mathrm{x}$ axis). No meaningful pattern is instead visible, except an irregular decrease for repeat revascularization.
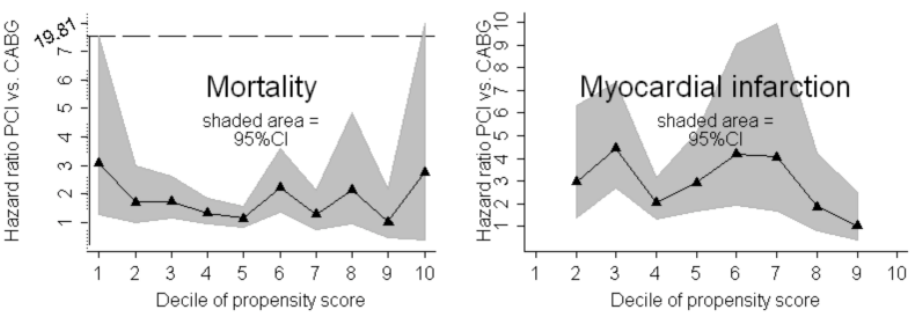

Figure 1. Trends of the Hazard Ratios of the various outcomes across the deciles of propensity score.

Decile 1 is most likely to receive $\mathrm{CABG}$ and decile 10 is most likely to receive PCI.
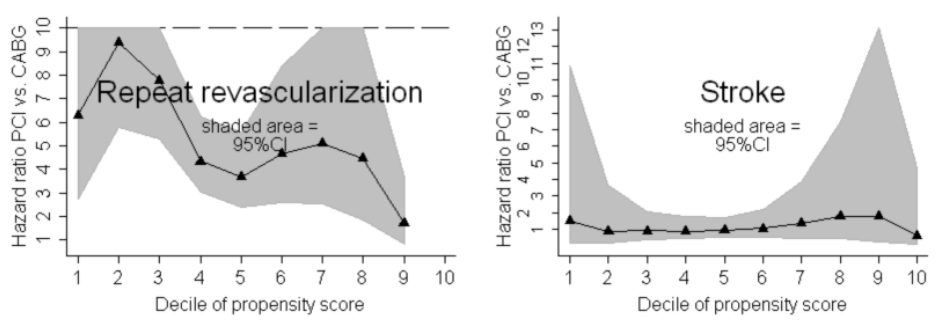

\section{Discussion}

In a regional population of revascularized CAD patients we found that the complex of characteristics that on average determined the choice between PCI and CABG had a minimal influence on the outcome of the procedures.

On one hand this may not appear surprising, given that it is the in-vivo confirmation of the scientific uncertainty presently surrounding this therapeutic choice. On the other hand, it contradicts the common belief that, despite scientific uncertainty, a careful and personalized formulation of the best revascularization strategy guided by clinical judgment can still lead to optimized outcomes.

Few studies before this one investigated the effect-modification of clinical and demographic characteristics not as single factors, but in combination, resembling the process of clinical judgment. The findings of these studies are consistent with ours because the relative outcomes associated with the two procedures were similar across quartiles ${ }^{[1]}$ or quintiles ${ }^{[17]}$ of PS or terciles of EuroSCORE and SYNTAX Score ${ }^{[4]}$. The categorization adopted in these studies may, however, have been too broad to unveil the heterogeneity of treatment-effect estimates ${ }^{[18,19]}$, while the one adopted here should yield stronger evidence.

A diminished importance of the tailoring process may have some positive consequences for the patients: their empowerment to the decision should increase. For example, if the overall survival advantage of CABG over PCI ${ }^{[17]}$ and absence of effect-modification is confirmed, most patients will be able take their own decision, provided they are well informed on the trade-off between a shorter, less stressful and cheaper hospital course with PCI and a lower long-term mortality with CABG. The latest clinical guidelines seem to be already following this tendency, as they recommend 
'Awareness that other factors such as sex, race, availability, technical skills, local results, referral patterns, and patient preference $[. .$.$] may have an impact on the decision making process, independently of clinical findings... { }^{[20]}$ The results of this study can contribute to the acceptance and diffusion of these principles.

In order to measure its impact on outcome, we have attempted to objectivize the process of clinical judgment, which is quite subtle and elusive. We adopted a methodology based on established statistical principles and recent research ${ }^{[16,21,22]}$, but there are some limitations. Most important is the assumption that the factors considered by clinicians were included in the PS calculation. We made every effort to ensure this by including in the PS all of the available variables. However, hidden confounding cannot be excluded, as usual in observational research. If any characteristic had been considered by clinicians but not recorded in the registries, the PS would have been less representative of the actual clinical judgment and some effect-modification might have been missed. It so, such information should become part the registries for further research.

Another possible limitation is that the propensity we calculated was an average over several institutions and many more clinicians. Because case-mix alone hardly justifies the large between-hospital variation in the procedures' frequency (Table 1), different attitudes or policies are also likely to exist. Therefore, the stronger effect-modification occurring in some hospitals might have gone undetected because of averaging.

A further limitation is that the number of cases in some categories was small. We cannot exclude that some characteristics scarcely represented in this population (e.g. isolated left main disease) may have caused important effect-modification.

Finally, although we believe that the pursuit of outcome optimization was predominant, some clinicians might have allowed other considerations (e.g. patient preference) to enter the decision-making, lowering the chances of this study to detect the real effect modification of the measured factors.

\section{Conflict of interests}

The authors declare that they have no conflict of interests.

\section{References}

[1] Hannan EL, Wu C, Walford G, Culliford AT, Gold JP, Smith CR, Higgins RS, Carlson RE, Jones RH. Drug-eluting stents vs. coronary-artery bypass grafting in multivessel coronary disease. N Engl J Med. 2008; 358: 331-41. PMid:18216353 http://dx.doi.org/10.1056/NEJMoa071804

[2] Li Y, Zheng Z, Xu B, Zhang S, Li W, Gao R, Hu S. Comparison of drug-eluting stents and coronary artery bypass surgery for the treatment of multivessel coronary disease: three-year follow-up results from a single institution. Circulation. 2009; 119: $2040-50$. PMid:19349321 http://dx.doi.org/10.1161/CIRCULATIONAHA.108.819730

[3] Javaid A, Steinberg DH, Buch AN, Corso PJ, Boyce SW, Pinto Slottow TL, Roy PK, Hill P, Okabe T, Torguson R, Smith KA, Xue Z, Gevorkian N, Suddath WO, Kent KM, Satler LF, Pichard AD, Waksman R. Outcomes of coronary artery bypass grafting versus percutaneous coronary intervention with drug-eluting stents for patients with multivessel coronary artery disease. Circulation. 2007; 116: I-200--I-206. PMid:17846304 http://dx.doi.org/10.1161/CIRCULATIONAHA.106.681148

[4] Park DW, Kim YH, Song HG, Ahn JM, Oh J, Kim WJ, Lee JY, Kang SJ, Lee SW, Lee CW, Park SW, Yun SC, Jung SH, Choo SJ, Chung CH, Lee JW, Park SJ. Long-term comparison of drug-eluting stents and coronary artery bypass grafting for multivessel coronary revascularization: 5-year outcomes from the Asan Medical Center-Multivessel Revascularization Registry. J Am Coll Cardiol. 2011; 57: 128-37. PMid:21211683 http://dx.doi.org/10.1016/j.jacc.2010.09.022

[5] Yang JH, Gwon HC, Cho SJ, Hahn JY, Choi JH, Choi SH, Lee YT, Lee SH, Hong KP, Park JE. Comparison of coronary artery bypass grafting with drug-eluting stent implantation for the treatment of multivessel coronary artery disease. Ann Thorac Surg. 2008; 85: 65-70. PMid:18154782 http://dx.doi.org/10.1016/j.athoracsur.2007.06.027

[6] Park SJ, Kim YH, Park DW, Yun SC, Ahn JM, Song HG, Lee JY, Kim WJ, Kang SJ, Lee SW, Lee CW, Park SW, Chung CH, Lee JW, Lim DS, Rha SW, Lee SG, Gwon HC, Kim HS, Chae IH, Jang Y, Jeong MH, Tahk SJ, Seung KB. Randomized trial of stents 
versus bypass surgery for left main coronary artery disease. N Engl J Med. 2011; 364: 1718-27. PMid:21463149 http://dx.doi.org/10.1056/NEJMoa1 100452

[7] Serruys PW, Morice MC, Kappetein AP, Colombo A, Holmes DR, Mack MJ, Ståhle E, Feldman TE, van den Brand M, Bass EJ, Van Dyck N, Leadley K, Dawkins KD, Mohr FW; SYNTAX Investigators. Percutaneous coronary intervention versus coronary-artery bypass grafting for severe coronary artery disease. N Engl J Med. 2009; 360: 961-72. PMid:19228612 http://dx.doi.org/10.1056/NEJMoa0804626

[8] Pocock SJ, Henderson RA, Rickards AF, Hampton JR, King SB 3rd, Hamm CW, Puel J, HuebW, Goy JJ, Rodriguez A. Meta-analysis of randomised trials comparing coronary angio- plasty with bypass surgery Lancet.1995; 346: $1184-9$. http://dx.doi.org/10.1016/S0140-6736(95)92897-9

[9] Bakhai A, Hill RA, Dundar Y, Dickson R, Walley T. Percutaneous transluminal coronary angioplasty with stents versus coronary artery bypass grafting for people with stable angina or acute coronary syndromes. Cochrane Database Syst Rev. 2005; 1 : CD004588. PMid:15674954

[10] Luo Y, Yu X, Chen F, Du X, He J, Gao Y, Zhang X, Zhang Y, Ren X, Lv S, Ma C. Impact of diabetes mellitus on patients with unprotected left main coronary artery lesion disease treated with either percutaneous coronary intervention or coronary-artery bypass grafting. Coron Artery Dis. 2012 Aug; 23(5): 322-9. PMid:22750912 http://dx.doi.org/10.1097/MCA.0b013e3283564961

[11] Kim WJ, Park DW, Yun SC, Lee JY, Lee SW, Kim YH, Lee CW, Park SW, Park SJ. Impact of diabetes mellitus on the treatment effect of percutaneous or surgical revascularization for patients with unprotected left main coronary artery disease: a subgroup analysis of the MAIN-COMPARE study. JACC Cardiovasc Interv. 2009 Oct; 2(10): 956-63. PMid:19850255 http://dx.doi.org/10.1016/j.jcin.2009.07.010

[12] Vignali L, Saia F, Manari A, Santarelli A, Rubboli A, Varani E, Piovaccari G, Menozzi A, Percoco G, Benassi A, Rusticali G, Marzaroli P, Guastaroba P, Grilli R, Maresta A, Marzocchi A. A. Long-term outcomes with drug-eluting stents versus bare metal stents in the treatment of saphenous vein graft disease (results from the REgistro Regionale AngiopLastiche Emilia-Romagna registry). Am J Cardiol. 2008; 101: 947-52. PMid:18359313 http://dx.doi.org/10.1016/j.amjcard.2007.11.055

[13] Di Eusanio M, Fortuna D, De Palma R, Dell'Amore A, Lamarra M, Contini GA, Gherli T, Gabbieri D, Ghidoni I, Cristell D, Zussa C, Pigini F, Pugliese P, Pacini D, Di Bartolomeo R. Aortic valve replacement: results and predictors of mortality from a contemporary series of 2256 patients. J Thorac Cardiovasc Surg. 2011; 141: 940-7. PMid:20599229

[14] Rosenbaum P. R. and Rubin, D. B. 'The central role of the propensity score in observational studies for causal effects', Biometrika. 1983; 70: 41-55. http://dx.doi.org/10.1093/biomet/70.1.41

[15] Austin PC, Mamdani MM. A comparison of propensity score methods: a case-study estimating the effectiveness of post-AMI statin use. Stat Med. 2006; 25: 2084-106. PMid:16220490 http://dx.doi.org/10.1002/sim.2328

[16] Kurth T, Walker AM, Glynn RJ, Chan KA, Gaziano JM, Berger K, Robins JM. Results of multivariable logistic regression, propensity matching, propensity adjustment, and propensity-based weighting under conditions of nonuniform effect. Am J Epidemiol. 2006; 163: 262-70. PMid:16371515 http://dx.doi.org/10.1093/aje/kwj047

[17] Weintraub WS, Grau-Sepulveda MV, Weiss JM, O'Brien SM, Peterson ED, Kolm P, Zhang Z, Klein LW, Shaw RE, McKay C, Ritzenthaler LL, Popma JJ, Messenger JC, Shahian DM, Grover FL, Mayer JE, Shewan CM, Garratt KN, Moussa ID, Dangas GD, Edwards FH. Comparative effectiveness of revascularization strategies. N Engl J Med. 2012 Apr 19; 366(16): 1467-76. PMid:22452338 http://dx.doi.org/10.1056/NEJMoa1 110717

[18] Greenland S. Dose-response and trend analysis in epidemiology: alternatives to categorical analysis. Epidemiology. 1995; 6: 356-365. PMid:7548341 http://dx.doi.org/10.1097/00001648-199507000-00005

[19] Bennette C, Vickers A. Against quantiles: categorization of continuous variables in epidemiologic research, and its discontents. BMC Medical Research Methodology. 2012; 12: 21. PMid:22375553 http://dx.doi.org/10.1186/1471-2288-12-21

[20] Task Force on Myocardial Revascularization of the European Society of Cardiology (ESC) and the European Association for Cardio-Thoracic Surgery (EACTS); European Association for Percutaneous Cardiovascular Interventions (EAPCI). Guidelines on myocardial revascularization. Eur Heart J. 2010; 31: 2501-55. PMid:20802248

[21] Sturmer T, Rothman KJ, Glynn RJ. Insights into Different Results from Different Causal Contrasts in the Presence of Effect-Measure Modification. Pharmacoepidemiol Drug Saf. 2006; 15: 698-709 PMid:16528796 http://dx.doi.org/10.1002/pds.1231

[22] Lunt M, Solomon D, Rothman K et al. British Society for Rheumatology Biologics Register; British Society for Rheumatology Biologics Register Control Centre Consortium. Different methods of balancing covariates leading to different effect estimates in the presence of effect modification. Am J Epidemiol. 2009; 169: 909-917. PMid:19153216 http://dx.doi.org/10.1093/aje/kwn391 